\title{
A potential novel combination therapy targeting survivin in renal cancer cells: Inhibition of survivin expression by topotecan and hexamethylene bisacetamide
}

\author{
AKINORI SATO, TAKAKO ASANO, KEIICHI ITO, MAKOTO SUMITOMO, \\ TOMOHIKO ASANO and MASAMICHI HAYAKAWA \\ Department of Urology, National Defense Medical College, 3-2 Namiki, Tokorozawa, Saitama 359-8513, Japan
}

Received October 29, 2008; Accepted February 28, 2009

DOI: 10.3892/mmr_00000116

\begin{abstract}
Survivin is an inhibitor of apoptosis and, as it is found in many tumors but not in most normal differentiated tissues, is an attractive target for cancer therapy. Survivin expression has been associated with cell proliferation in renal cancer. We previously demonstrated the possibility of treating renal cancer by suppressing survivin expression using the topoisomerase I inhibitor topotecan and survivin-specific siRNA. In the present study, we used Caki-1 cells to investigate the possibility of treating renal cancer by combining topotecan and the hybrid polar compound hexamethylene bisacetamide (HMBA) to completely suppress survivin expression. HMBA is known to induce cell differentiation. This warrants the testing of the ability of HMBA to suppress survivin, which is associated not only with carcinogenesis but also with differentiation. Both topotecan and HMBA were shown to suppress survivin expression and cell proliferation. However, the combination of topotecan and HMBA suppressed survivin expression completely and more effectively inhibited cell proliferation, leading to apoptosis. Combination therapy using topotecan and HMBA might thus be effective treatment for advanced renal cancer.
\end{abstract}

\section{Introduction}

Patients with metastatic renal cell carcinoma (RCC) have a 5 -year survival rate of only 5\% (1), and its current treatment options do not offer promising results. Chemotherapy and radiotherapy are usually ineffective (2), and only $10-20 \%$ of RCC patients respond to interferon therapy (3). Numerous combination therapies have been evaluated, but none have yielded satisfactory response rates (4). Tyrosine kinase inhi-

Correspondence to: Dr Akinori Sato, Department of Urology, National Defense Medical College, 3-2 Namiki, Tokorozawa, Saitama 359-8513, Japan

E-mail: zenpaku@ndmc.ac.jp

Key words: renal cancer, survivin, topotecan, hexamethylene bisacetamide bitors have recently been introduced as a new treatment modality, but have not proved to be curative in clinical trials $(5,6)$

Abnormalities in the control of apoptosis, the process by which a cell undergoes a suicide program that results in cell death, play an important role in cancer development. Survivin, a member of the inhibitor of apoptosis (IAP) family of proteins, is involved in the control of mitotic progression and the inhibition of apoptosis (7). It is an exciting target for cancer therapy because it is found in many tumors, but not in most normal differentiated tissues (8).

We have already shown that the expression of survivin is associated with cell proliferation in RCC cell lines, and that the combination of the topoisomerase I inhibitor topotecan and survivin-specific small interfering RNA (siRNA) synergistically inhibits survivin expression and cell proliferation (9-11). Targeting survivin may thus be an effective method for treating advanced RCC.

Hexamethylene bisacetamide (HMBA) is a hybrid polar compound that can induce the terminal differentiation of transformed cells (12) by modulating their membrane surface potential, which may activate a signaling pathway $(13,14)$. HMBA has also been demonstrated to induce apoptosis $(15,16)$. Since survivin is expressed in the human fetal kidney, and since the expression of survivin in embryonic and fetal development might contribute to tissue homeostasis and differentiation (17), HMBA has the potential to regulate survivin expression and induce apoptosis. However, the effect of HMBA on survivin expression in renal cancer cells has yet to be investigated.

In exploring the possibility of treating advanced RCC by suppressing survivin expression in various RCC cell lines, we found a higher level of survivin expression in Caki-1 cells (11). We therefore used Caki-1 cells in the present study to investigate the effectiveness of a novel combination therapy using topotecan and HMBA to inhibit survivin expression and cell proliferation. We found that the combination of HMBA and topotecan suppressed the expression of survivin completely and inhibited cell proliferation. To the best of our knowledge, this is the first report to reveal the effect of HMBA on survivin expression. Combining HMBA and topotecan is thus a promising approach to the treatment of advanced renal cancer. 


\section{Materials and methods}

Cell culture. The Caki-1 RCC cell line was obtained from American Type Culture Collection (Rockville, MD, USA). Cells were grown in DMEM medium containing $10 \%$ fetal bovine serum and $0.3 \%$ penicillin-streptomycin (Invitrogen, Carlsbad, CA, USA).

Treatment with HMBA and topotecan. Cells were plated in 6-well culture plates (for Western blot analysis and cell cycle analysis) or 96-well culture plates (for cell proliferation assay) one day before treatment. Cells were treated in DMEM medium containing either HMBA (LKT Laboratories, St. Paul, MN, USA) (0-20 mM), topotecan $(0-1 \mu \mathrm{g} / \mathrm{ml})$ or both agents for $48 \mathrm{~h}$, and were assayed for survivin expression and cell proliferation.

Cell proliferation assay. Cells were plated in a 96-well culture plate one day before treatment and then incubated under the indicated conditions for 24 or $48 \mathrm{~h}$, after which cell proliferation was determined using the MTT assay or Alamar Blue assay (Biosource International, Camarillo, CA, USA).

Cell cycle analysis. After treatment under the indicated conditions, cells were washed with PBS and harvested by trypsinization. The cells were resuspended in citrate buffer and stained with propidium iodide following the method described by Vindelov et al (18). They were then analyzed by flow cytometry using the Cell Quest program for the calculation of the different cell cycle phases.

Western blot analysis. Cells were homogenized in RIPA buffer (50 mM Tris, $150 \mathrm{mM} \mathrm{NaCl}, 1 \mathrm{mM}$ EDTA, $1 \mathrm{mM}$ PMSF, $0.25 \%$ sodium deoxycholate, $1 \mathrm{mM} \mathrm{Na} \mathrm{VO}_{4}, 1 \mathrm{mM} \mathrm{NaF}$, $1 \%$ NP-40 and protease inhibitor mixture) for $15 \mathrm{~min}$ on ice. Protein concentrations were obtained using the DC Protein Assay Reagent (Bio-Rad Laboratories, Hercules, CA, USA). Samples were mixed with loading buffer, resolved by $12.5 \%$ SDS-PAGE, and transferred onto nitrocellulose membranes. After blocking with 5\% dry skim milk, the membranes were incubated for $1 \mathrm{~h}$ or overnight with anti-survivin rabbit polyclonal antibody (Alpha Diagnostic International, San Antonio, TX, USA). The membranes were then incubated with a biotinylated secondary goat anti-rabbit antibody (Bio-Rad Laboratories) for $1 \mathrm{~h}$ at room temperature and subsequently with a streptavidin-biotinylated alkaline phosphatase complex (Bio-Rad Laboratories) for an additional hour at room temperature. Immunoreactivity was detected using an alkaline phosphatase substrate kit following the manufacturer's protocol (Bio-Rad Laboratories). The level of survivin expression was semi-quantified using the public domain NIH Image program and normalized to the level of ß-actin expression.

\section{Results}

We evaluated the effect of HMBA alone and in combination with topotecan on survivin expression and cell proliferation. The effect of topotecan and/or HMBA on cell proliferation was minimal at $24 \mathrm{~h}$ after treatment. However, a 48-h treatment with topotecan or HMBA decreased cell proliferation in a dose-dependent manner. Furthermore, cell growth was dramatically inhibited by $48 \mathrm{~h}$ of treatment with the combination of topotecan and HMBA (Fig. 1A). Microscopic examination also supported the significant effect of this combination therapy (Fig. 1B). Treatment with either HMBA or topotecan for $48 \mathrm{~h}$ decreased survivin expression, while treatment with a combination of HMBA and topotecan decreased survivin expression completely (Fig. 2). Cell cycle analysis was used to evaluate changes in the cell cycle and apoptosis induced by HMBA and topotecan. The sub-G1 fraction, containing apoptotic cells, was markedly increased, and the G2/M fraction was eliminated by the combination of HMBA and topotecan (Fig. 3). Considering the cell cycle-dependent expression of survivin, we believe that the decreased survivin expression observed was due to the disappearance of the G2/M phase. We have thus demonstrated, for the first time and to the best of our knowledge, the combined effect of HMBA and topotecan on survivin expression and cell proliferation in renal cancer cells.

\section{Discussion}

Survivin is an IAP protein associated with carcinogenesis, tumor progression and decreased survival (19). Since survivin is detected in many tumors but not in most normal differentiated tissues (8), it has been recognized as a novel target for cancer therapy. We previously showed that survivin expression is associated with cell proliferation in RCC cells (9), and that it might be possible to treat RCC using a combination of topotecan and survivin-specific siRNA. Although some successful cases of siRNA application in vivo have been reported $(20,21)$, it is not always easy to achieve high transfection efficiency with liposomes in vivo. We therefore explored the feasibility of treating RCC by using topotecan and HMBA in combination to suppress survivin expression completely.

Topotecan is a topoisomerase I inhibitor used in the treatment of various cancers (22-24). Its effectiveness in renal cancer patients has been investigated in only one Phase II study (25), and its effect on survivin expression has been investigated in two studies, one with prostate cancer cells (26) and the other with renal cancer cells (11). Both these studies found survivin expression to be decreased by topotecan. However, the exact mechanism by which topotecan decreased survivin expression remains unknown. Topotecan was recently shown to inhibit epidermal growth factor receptor (EGFR) expression (27). Since survivin is increased by epidermal growth factor (EGF) $(28,29)$, the inhibition of EGFR expression may be the mechanism by which topotecan suppresses survivin expression.

HMBA is a hybrid polar compound that induces terminal differentiation of transformed cells (12). Its anti-tumor effect has been evaluated in various cancer cells, mainly blood malignancy $(15,16,30)$. A Phase II clinical trial for HMBA treatment of myelodysplatic syndrome and acute myelogenous leukemia was conducted (31). HMBA modulates the membrane surface potential of transformed cells, and this might activate a signaling pathway $(13,14)$. Some studies revealed that $\mathrm{HMBA}$ can induce apoptosis and decrease 
A

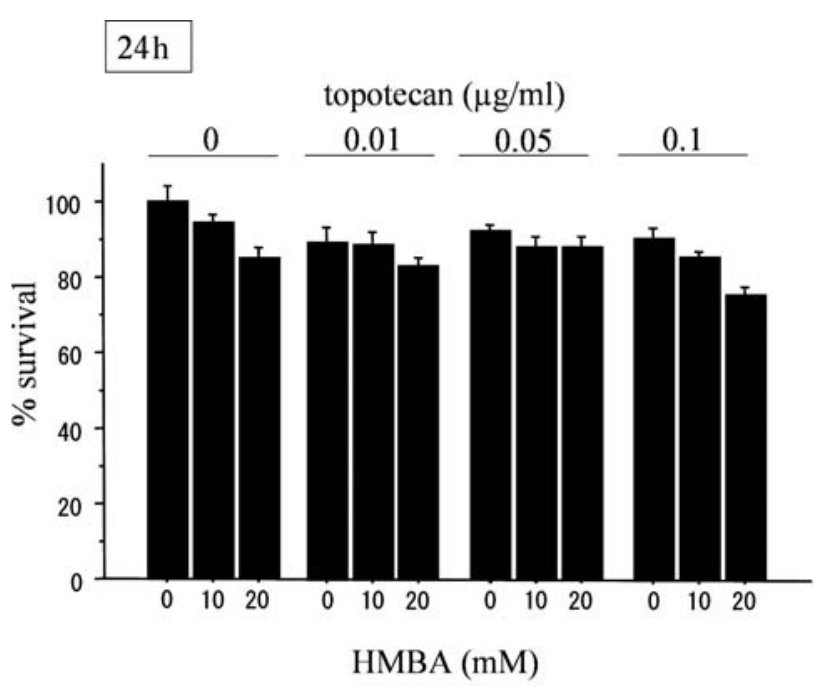

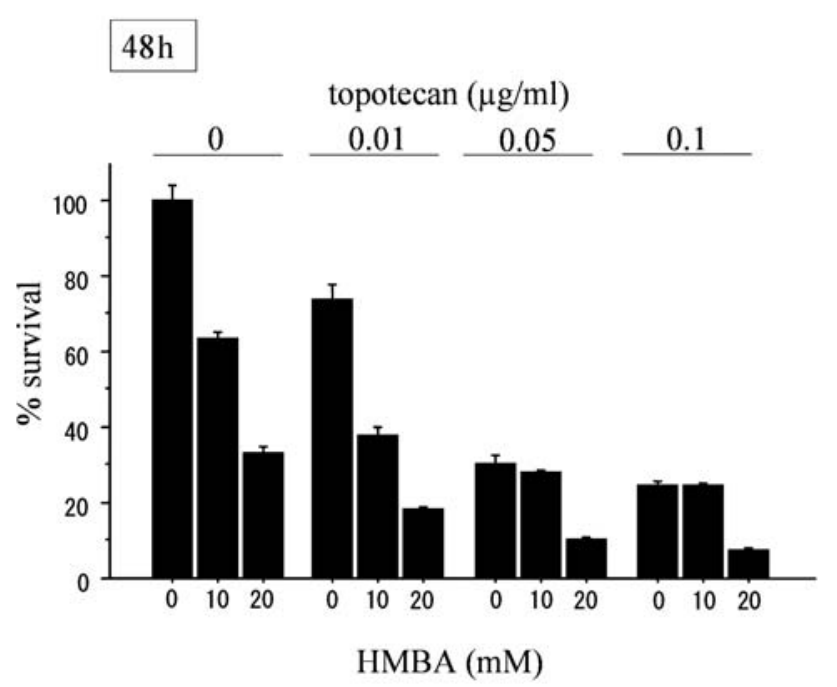

$\operatorname{HMBA}(\mathrm{mM})$

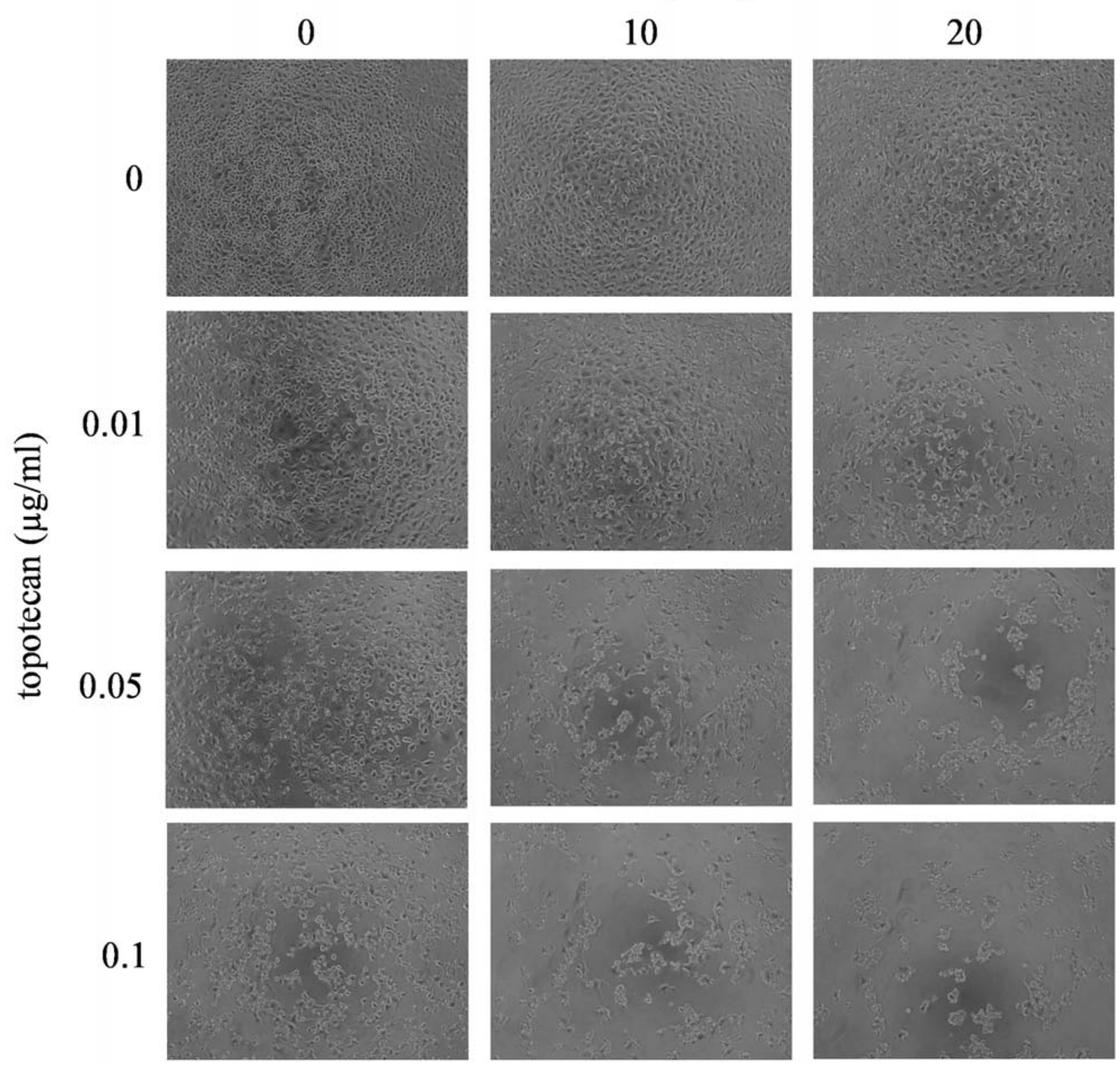

Figure 1. Inhibition of cell proliferation by topotecan and/or HMBA. (A) Cell viability using the MTT or Alamar Blue assay after a 24- and 48-h treatment. (B) Microscopic examination. Cell proliferation was synergistically inhibited by the combination of topotecan and HMBA. 


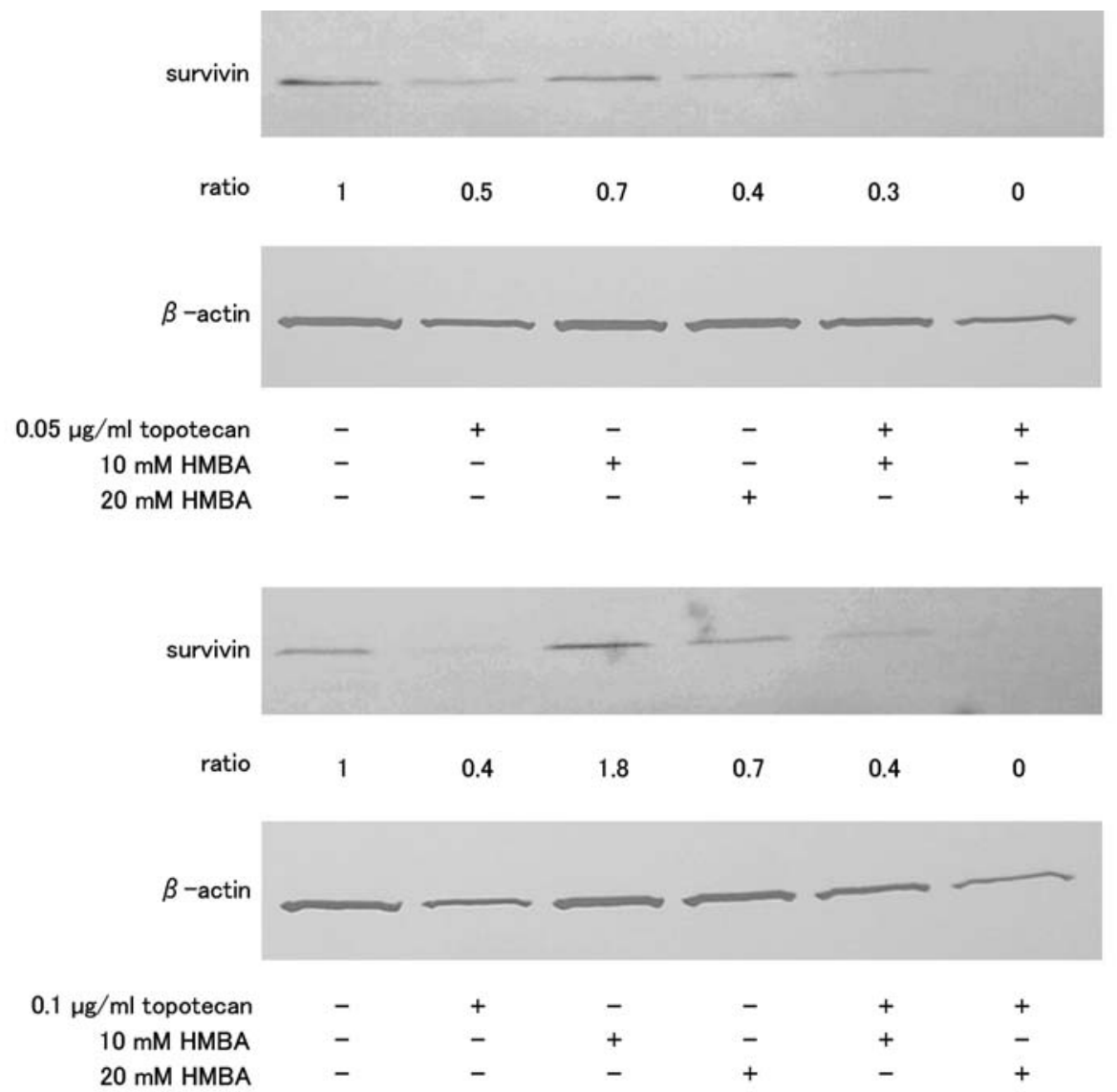

Figure 2. Inhibition of survivin expression by topotecan and/or HMBA. Western blot analysis of survivin after a 48-h treatment. Survivin expression was completely suppressed by the combination of topotecan and HMBA. Ratio = survivin level/control survivin level (both levels were normalized by the corresponding level of $\beta$-actin).

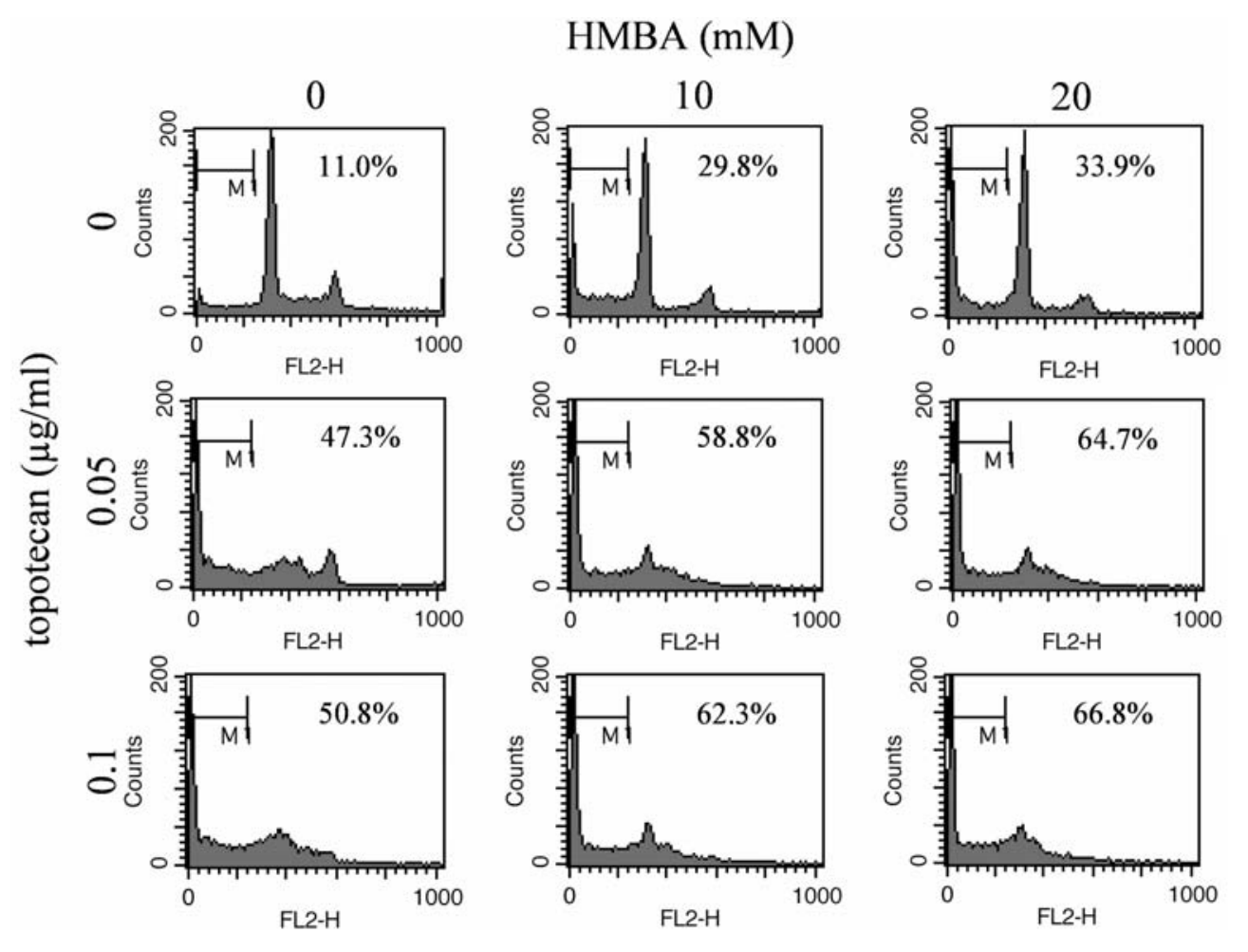

Figure 3. Cell cycle analysis $48 \mathrm{~h}$ after treatment with topotecan and/or HMBA. The percentage of the cells in the sub-G1 fraction was measured. The combination of topotecan and HMBA increased the sub-G1 fraction and eliminated the G2/M fraction. 
BCL-2 expression $(15,16)$. On the assumption that expression of survivin is associated with apoptosis and differentiation (17), we postulated that HMBA could regulate survivin expression. In the present study, HMBA decreased survivin expression and inhibited cell proliferation in a dose-dependent fashion. Cell cycle analysis also revealed an HMBA-induced increase in the sub-G1 fraction, which contained apoptotic cells. Signaling pathways influenced by HMBA have not been fully understood. It has been demonstrated that HMBA decreases cyclin-dependent kinase (cdk) 4 activity and induces the hypophosphorylation of retinoblastoma protein ( $\mathrm{Rb})(32)$, which has also been thought to play a role in renal cancer (33). Jiang et al previously showed that Rb can bind to the survivin promoter region and repress survivin transcription (34). One can therefore assume that HMBA decreases survivin expression through the activation of $\mathrm{Rb}$.

The combination of topotecan and HMBA suppressed survivin expression completely. It has been demonstrated that $\mathrm{Rb}$ hypophosphorylation can be induced by blocking the EGF receptor (35). One possible explanation for the complete suppression of survivin expression by the combination of topotecan and HMBA might therefore be the activation of $\mathrm{Rb}$ by further hypophosphorylation. According to cell cycle analysis, combination therapy increased the sub-G1 fraction and decreased the G2/M fraction. Survivin has been shown to be expressed in the $\mathrm{G} 2 / \mathrm{M}$ phase in a cell cycle-dependent manner (36). The decrease in the G2/M fraction by combination therapy may therefore account for the suppression of survivin expression, and may also be related to the inhibition of cell cycle progression by $\mathrm{Rb}$ (37).

The drawback of the clinical use of HMBA is its high optimal concentration and toxic side effects, such as thrombocytopenia $(31,38)$. To overcome these problems, second generation hybrid polar compounds with $\sim 2000$-fold greater potency have been developed (38). Unlike HMBA, these novel compounds can inhibit histone deacetylases such as trichostatin A (39). Further investigation of these second generation hybrid polar compounds will be required before our combination therapy using topotecan and a hybrid polar compound can be used in the clinical treatment of renal cancer.

In summary, the combination of HMBA and topotecan completely suppressed survivin expression in Caki-1 cells and inhibited their proliferation. To the best of our knowledge, this is the first study to investigate the influence of HMBA on survivin expression in renal cancer cells.

\section{References}

1. Motzer RJ, Bander NH and Nanus DM: Renal-cell carcinoma. N Engl J Med 335: 865-875, 1996.

2. Mulders P, Figlin R, deKernion JB, Wiltrout R, Linehan M, Parkinson D, deWolf $\mathrm{W}$ and Belldegrun A: Renal cell carcinoma: recent progress and future directions. Cancer Res 57: 5189-5195, 1997.

3. Pittman K and Selby P: The management of renal cell carcinoma. Crit Rev Oncol Hematol 16: 181-200, 1994.

4. Autenrieth M, Heidenreich A and Gschwend JE: Systemic therapy of metastatic renal cell carcinoma. Urologe A 45: 594-599, 2006.

5. Escudier B, Eisen T, Stadler WM, Szczylik C, Oudard S, Siebels M, Negrier S, Chevreau C, Solska E, Desai AA, Rolland F, Demkow T, Hutson TE, Gore M, Freeman S, Schwartz B, Shan M, Simantov R and Bukowski RM; TARGET Study Group: Sorafenib in advanced clear-cell renal-cell carcinoma. N Engl J Med 356: 125-134, 2007.
6. Ratain MJ, Eisen T, Stadler WM, Flaherty KT, Kaye SB, Rosner GL, Gore M, Desai AA, Patnaik A, Xiong HQ, Rowinsky E, Abbruzzese JL, Xia C, Simantov R, Schwartz B and O'Dwyer PJ: Phase II placebo-controlled randomized discontinuation trial of sorafenib in patients with metastatic renal cell carcinoma. J Clin Oncol 24: 2505-2512, 2006.

7. Altieri DC and Marchisio PC: Survivin apoptosis: an interloper between cell death and cell proliferation in cancer. Lab Invest 79: 1327-1333, 1999.

8. Ambrosini G, Adida C and Altieri DC: A novel anti-apoptosis gene, survivin, expressed in cancer and lymphoma. Nat Med 3: 917-921, 1997.

9. Sato A, Oya M, Ito K, Mizuno R, Horiguchi Y, Umezawa K, Hayakawa M and Murai M: Survivin associates with cell proliferation in renal cancer cells: Regulation of survivin expression by insulin-like growth factor-1, interferon- $\gamma$ and a novel $\mathrm{NF}-\kappa \mathrm{B}$ inhibitor. Int J Oncol 28: 841-846, 2006.

10. Sato A, Ito K, Asano T, Sumitomo M, Asano T and Hayakawa M: Synergistic effect of survivin-specific small interfering RNA and topotecan in renal cancer cells: Topotecan enhances liposome-mediated transfection by increasing cellular uptake. Int J Oncol 30: 695-700, 2007.

11. Sato A, Ito K, Asano T, Sumitomo M, Asano $\mathrm{T}$ and Hayakawa M: Topotecan and small interfering RNA suppress survivin expression synergistically in Caki-1 renal cancer cells: Direct suppression of survivin and enhancement of transfection efficiency by topotecan. Int J Oncol 32: 171-176, 2008.

12. Marks PA, Richon VM, Kiyokawa $H$ and Rifkind RA: Inducing differentiation of transformed cells with hybrid polar compounds: a cell cycle-dependent process. Proc Natl Acad Sci USA 91: 10251-10254, 1994.

13. Arcangeli A, Carla M, Del Bene MR, Becchetti A, Wanke E and Olivotto M: Polar/apolar compounds induce leukemia cell differentiation by modulating cell-surface potential. Proc Natl Acad Sci USA 90: 5858-5862, 1993.

14. Tsiftsoglou AS and Wong W: Molecular and cellular mechanisms of leukemic hemopoietic cell differentiation: an analysis of the Friend system. Anticancer Res 5: 81-99, 1985.

15. Siegel DS, Zhang X, Feinman R, Teitz T, Zelenetz A, Richon VM, Rifkind RA, Marks PA and Michaeli J: Hexamethylene bisacetamide induces programmed cell death (apoptosis) and down-regulates BCL-2 expression in human myeloma cells. Proc Natl Acad Sci USA 95: 162-166, 1998.

16. Ruefli AA, Smyth MJ and Johnstone RW: HMBA induces activation of a caspase-independent cell death pathway to overcome P-glycoprotein-mediated multidrug resistance. Blood 95: 2378-2385, 2000 .

17. Adida C, Crotty PL, McGrath J, Berrebi D, Diebold J and Altieri DC: Developmentally regulated expression of the novel cancer anti-apoptosis gene survivin in human and mouse differentiation. Am J Pathol 152: 43-49, 1998.

18. Vindelov LL, Christensen IJ and Nissen NI: A detergent-trypsin method for the preparation of nuclei for flow cytometric DNA analysis. Cytometry 3: 323-327, 1983.

19. LaCasse EC, Baird S, Korneluk RG and MacKenzie AE: The inhibitors of apoptosis (IAPs) and their emerging role in cancer. Oncogene 17: 3247-3259, 1998.

20. Sørensen DR, Leirdal M and Sioud M: Gene silencing by systemic delivery of synthetic siRNAs in adult mice. J Mol Biol 327: 761-766, 2003.

21. Sioud M and Sørensen DR: Cationic liposome-mediated delivery of siRNAs in adult mice. Biochem Biophys Res Commun 312: 1220-1225, 2003.

22. Eckardt JR: Emerging role of weekly topotecan in recurrent small cell lung cancer: Oncologist 9 (Suppl 6): 25-32, 2004.

23. McGuire WP, Blessing JA, Bookman MA, Lentz SS and Dunton CJ: Topotecan has substantial antitumor activity as firstline salvage therapy in platinum-sensitive epithelial ovarian carcinoma: A Gynecologic Oncology Group Study. J Clin Oncol 18: 1062-1067, 2000.

24. Moore DH: Chemotherapy for recurrent cervical carcinoma. Curr Opin Oncol 18: 516-519, 2006.

25. Law TM, Ilson DH and Motzer RJ: Phase II trial of topotecan in patients with advanced renal cell carcinoma. Invest New Drugs 12: 143-145, 1994.

26. Griffith TS and Kemp TJ: The topoisomerase I inhibitor topotecan increases the sensitivity of prostate tumor cells to TRAIL/ Apo-2L-induced apoptosis. Cancer Chemother Pharmacol 52: 175-184, 2003. 
27. Mialon A, Sankinen M, Soderstrom H, Junttila TT, Holmstrom T, Koivusalo R, Papageorgiou AC, Johnson RS, Hietanen S, Elenius $\mathrm{K}$ and Westermarck J: DNA topoisomerase I is a cofactor for c-Jun in the regulation of epidermal growth factor receptor expression and cancer cell proliferation. Mol Cell Biol 25: 5040-5051, 2005.

28. Ai Z, Yin L, Zhou X, Zhu Y, Zhu D, Yu Y and Feng Y: Inhibition of survivin reduces cell proliferation and induces apoptosis in human endometrial cancer. Cancer 107: 746-756, 2006.

29. Qiu L, Wang Q, Di W, Jiang Q, Schefeller E, Derby S, Wanebo H, Yan B and Wan Y: Transient activation of EGFR/ AKT cell survival pathway and expression of survivin contribute to reduced sensitivity of human melanoma cells to betulinic acid. Int J Oncol 27: 823-830, 2005.

30. Palumbo C, Albonici L, Bei R, Bocci C, Scarpa S, Di Nardo P and Modesti A: HMBA induces cell death and potentiates doxorubicin toxicity in malignant mesothelioma cells. Cancer Chemother Pharmacol 54: 398-406, 2004.

31. Andreeff M, Stone R, Michaeli J, Young CW, Tong WP, Sogoloff H, Ervin T, Kufe D, Rifkind RA and Marks PA: Hexamethylene bisacetamide in myelodysplastic syndrome and acute myelogenous leukemia: a phase II clinical trial with a differentiation-inducing agent. Blood 80: 2604-2609, 1992.

32. Kiyokawa H, Richon VM, Rifkind RA and Marks PA: Suppression of cyclin-dependent kinase 4 during induced differentiation of erythroleukemia cells. Mol Cell Biol 14: 7195-7203, 1994.
33. Lai S, Benedict WF, Silver SA and El-Naggar AK: Loss of retinoblastoma gene function and heterozygosity at the RB locus in renal cortical neoplasms. Hum Pathol 28: 693-697, 1997.

34. Jiang Y, Saavedra HI, Holloway MP, Leone G and Altura RA: Aberrant regulation of survivin by the RB/E2F family of proteins. J Biol Chem 279: 40511-40520, 2004.

35. Mendelsohn J: The epidermal growth factor receptor as a target for cancer therapy. Endocr Relat Cancer 8: 3-9, 2001.

36. Li F, Ambrosini G, Chu EY, Plescia J, Tognin S, Marchisio PC and Altieri DC: Control of apoptosis and mitotic spindle checkpoint by survivin. Nature 396: 580-584, 1998.

37. Giacinti $\mathrm{C}$ and Giordano A: RB and cell cycle progression. Oncogene 25: 5220-5227, 2006.

38. Richon VM, Webb Y, Merger R, Sheppard T, Jursic B, Ngo L, Civoli F, Breslow R, Rifkind RA and Marks PA: Second generation hybrid polar compounds are potent inducers of transformed cell differentiation. Proc Natl Acad Sci USA 93: 5705-5708, 1996.

39. Richon VM, Emiliani S, Verdin E, Webb Y, Breslow R, Rifkind RA and Marks PA: A class of hybrid polar inducers of transformed cell differentiation inhibits histone deacetylases. Proc Natl Acad Sci USA 95: 3003-3007, 1998. 